\title{
The Impact of Computer-Assisted Language Learning (CALL) on Grammar Acquisition by Saudi Learners
}

\author{
Nesreen Saud Alahmadi \\ Assistant Professor \\ Tiabah University \\ Madinah, Saudi Arabia
}

\begin{abstract}
This study examined the impact of computer-assisted language learning (CALL) on grammar acquisition forEnglish as a foreign language (EFL) in a Saudi context. The hypothesis of this study wasto investigate if CALL has a positive impact on learning grammar. The participants of this study were 150female learners froma preparatory year who study English language as a core module. The students were tested in their English language proficiency using the Oxford Online Placement Test and scored at an upper intermediate level.Students were assigned into one of two groups, control orexperimental.The control group had the material in printed text from the course book. The experimental group was given the same materials in addition to extra software exercises using anonline learning management system (LMS). Two types of tests (pre and post) were employed to compare the students' language proficiency in grammar. The results of the post-test supported thehypothesis of this research byfinding that there wasa substantialdifference in the results between the control and the experimental groups in the level of grammar acquisition for grammatical rules and forms. The findings of this research carry significant implications for second/foreign language learning, English language practitioners, andseconed language acquisition researchers.
\end{abstract}

Keywords: Computer-Assisted Language Learning, English Language, Grammar Acquisition, Saudi Arabia.

\section{1-Introduction}

In recent years, the enormous evolution of information technology and communications has created unlimited changes not only in societies and globalization but also in education. The use of computers and online resources at educational institutions has increased extensively which had a crucial influence on education developments. Computer-assisted language learning (CALL) is one of the vital tools and techniques that has a significant impact on improvingthe language competencies of learners. The effectiveness of CALL on language learning has been investigated by many studies around the world. Most research results have validated a positive role of CALL on language learning and language proficiency. In fact, this kind of technology in teaching and learning has been amplified in many educational perspectives. It has increased learners' creativity, productivity and assisted withindividual learning differences. CALL has been used for many different approaches in language learning, such as language practice, teaching drills, teaching methods andeven as an effective tool to raise discussions and language interaction. Today, using computers in learning and teaching is emerging as anessentiallanguage learning resource, which has received a great deal of attention in the education field. For example, Crossman (1997) stated that web-based learning has been used extensively more than any other kind of technology. Also, foreign language teachers are challenged by whetheror not to use technologyin ongoing language teaching. On the other hand, some language teachers believe in the significant role that computer language learning has on enhancing their students' language competence.

CALL is concisely defined in a formative work by Levy (1997) as "the search for and study of applications of the computer in language teaching and learning" (p.1). Also, Chapelle (2001) asserted that this definition is widely used to pinpoint the field of technology and second language (L2) learning and teaching in spite of the differing terms, whichhave caused continualsuggestionsto revise the termas using computers in language learning has taken on a broader scope. For example, Beatty (2003) characterises the term CALL with the following statement"a definition of CALL that accommodates its changing nature is any process in which a learner uses a computer and, as a result, improves his or her language" (p.7). Initially, in the past, the innovative uses of software in learning thatcontained drills, practices and exercises were used without having these materialsavailablefor onlineaccess. Thus, with the advanced use of technology, CALL started to become more active and more widespread with arapid increaseinvarious media and theirintegration into the computer systemsforlearning (Pusack\& Otto, 1990). Thus, the current study examined the impact of computer-assisted language learning on grammar learning in aSaudi EFL context. The research question was: does computer-assisted language learning have any impact on grammar acquisition? 


\section{2-Background}

The use of CALL originated in the 1960s. After that, CALL projects in which computer programmes were developed to serve the purpose of processing large amounts of informationwere introduced in some universities in the US and ran up until the late 1970s. In fact, the start of the PLATO project, at the University of Illinois in 1960, is considered to be a significant landmark in the advanced use of CALL (Marty 1981). Then, the development of personal computers allowed this kind of technology to become widespread for personal use which wasrestricted tothe use of institutions in the past, that could afford large computer systems. This resulted in more developments of CALLprogrammes for application in different fields. However, in the late 1980s, the different applications of CALLexpanded into a range of initiative technologies that focused on communicative approaches and methods in education. Thereby, CALL began to be establishedas afoundation of many important areas for educational researchin the field of teaching and learning. The programmes used to present CALL in educationwerefundamentallybased on presenting a stimulus to learners forwhich they needed to provide certainresponses. In early uses of CALL, the only way that learners couldrespondto questions on the screen was by using a keyboard.However, with the current revolution in using CALL, relying on the traditional uses of CALL are replaced by the integration of learning with technology to enhance learning skills.

With the development of CALL in the education field, researchers have categorised this development into three different phases (Warschauer, 1996, as cited in Pirasteh, 2014).The first phase of CALL, between the 1960s and 1970s, was founded on the basics of behaviourist theories of learning in second language acquisition. Some programs of this phase referred to as "practice and drills" focused on repetitive language drills to enhance second language practice. The second phase of CALL focused on teaching via the communicative approach, which became very prominentin the 1970s and 1980s. The argument forthis approach was that the efficiency in usingthe drill and practice programs did not deliver enough language communication skills which are greatly valued in languagelearning.The third phase of CALL was based on integrative approaches that focused on the development of technology to include the internet and multimedia in all sectors of education.

CALL programs are currentlyemployed to assist learners developing their second language competence and skills, including grammar, vocabulary, etc. andto enhance the learner's understanding of foreign cultural values and attitudes. The increasing numbers of studiesin using CALL in this respect suggest thefollowing programs and materials that can be used effectively in teaching and learning foreign languages: 1) specific software of CALL, this includes applications designed to assist language learning, such as interactive language learning, web-based quizzes and exercises; 2) webbased educational and learning programs, such as online encyclopaedias, dictionaries and news/magazine sites, web publishing, online blogs, wiki, etc.; 3) generic software which includes applications that are designed for general educational and non-educationalpurposes, such as Microsoft office programs and software;and 4)computer-mediated communication (CMC) programs, such as online chat, e-mail, message boards and discussion forums and blogs (Pirasteh, 2014).

\subsection{The Use of CALL and Second Language Acquisition}

CALL has been linked to second language research since the late 1970s. According to (Chapelle, 2008), second/foreign language learners need to work on L2 or the target language interactively either in a learning environment (direct contact with people) or with computer programs that enhance their language competenceand sharpen their current L2 skills. In fact, some CALL tasks which allow the learners to be part of the assessment or instruction, or the materials used in the learning, might be presented to learners as computer-based tasks (Chapelle, 2001). These tasks can be implemented in second language research to serve two purposes: either they can be used to examine some of the learning conditions about which second language acquisition (SLA) researchers would test their hypotheses on, or they could be used to collect data that allow linguists and language practitioners to make judgments about a learner's competence and L2 language knowledge. Many studies in SLA have been conducted to test and identify the outcomes of some instructionally designed programs or features that help learners to use the target language (Larsen-Freeman \& Long, 1991). Therefore, some SLA research has been especially conducted to test and gather information about the impact of these programs on second language learning. For instance, the studies by Hulstijn (1997) tested the effectiveness of CALL tasks on the "value of explicit versus implicit instruction". According to Chapelle (2008), these tasks were tested in a way in which "the degree of control over the instructional conditions in such research far exceeds what can be obtained in classroom research where teachers are to teach in a particular way" (p. 99).

Consequently, more studies have been conducted to invistigate the use of CALL in second language learning. For example, the relationship between inductive and deductive grammar and its interaction with individual differences in L2 learners' cognitive styles were examined by Abraham (1985). Moreover, Sanz and Morgan (2004) investigated the impact of the presence or absence of grammar explanation in Spanish and feedback on the acquisition of word order. 
Saeidi and Yusef (2012) tested the effect of CALL on reading comprehension in an Iranian context, which helped to increase the proficiency of reading skills for those learners. Also, Doughty (1991) examined the impact of varied input conditions using CALL for the acquisition of some relative clauses in reading. In fact, for the last two decades, the use of CALL has been proven to be reliable in some aspects of instructed second language acquisition research, such as the assessment of individual differences and the testing of learners' language competence in L2 skills. Also, some new types of research in CALL have been developed to test the second language learning tasks with learners. This research contains different interest areas in SLA, such as using CALL to enhance learning input (Levy \& Stockwell, 2007). Others have focused on feedback given to learners by CALL in order to improve their learning competence (Nagata, 1993; Yoshii \&Flaitz, 2002). Second language acquisition in written interaction has also been studied (Blake, 2000).

In addition to the studies conducted to test learners' language competence, CALL took a broader scope in SLA that included discrete error analysis and feedback, which were the most common features of using traditional CALL. Also, the design of some sophisticated programs attempted to analyse L2 learner's responses, highlight language errors, branch to assets and provide remedial activities to overcome learners' errors. (Skehan, 1998; Smith, 2004).

\subsection{CALL in Saudi Arabia and the Arab world}

CALL was first introduced in the education system in Saudi Arabia in the early 1990s, and has expanded tremendously in the past 30 years. Originally, CALL was only used on a limited basis in the educational sectors for administrative purposes before public schools started to use computers as part of the Saudi national curriculum at the different educational stages: elementary, intermediate, and high (Alshumaim, \& Alhassan, 2010). Some studies in Saudi Arabia were conducted to test the impact of CALL programs in writing skills in comparison to the traditional methods in which the results indicated great improvement in the level of L2 learner's writing competence when using CALL. (Alsouki, 2001). Moreover, Al-Qomoul (2005) in his study of using CALL found that applying instructional software programs had significantly enhanced students' L2 performance versus using the traditional methods. Hashmi (2016) also tested the use of CALL in Saudi EFL classes and its impact on the learning process.

Likewise, in the Arab world, some studies have continued to study the effects of CALL for second language learning. For example, Al-Abdel Halim (2009) validated the efficacy of CALL in refining Jordanian secondary learners' reading comprehension. Bataineh and Hani (2011) conducted a study to examine the effects of CALL programs on Jordanian sixth grade learners' language proficiency in English as a foreign language. The outcome of this study revealed that language acquisition was greatly influenced by the means of instruction. Additionally, Alresheed, et al. (2015) piloted a study on integrating CALL in a Saudi school as a change model of L2 teaching. Their study showed that CALL had a great impact on enhancing teaching English in high schools in spite of some barriers, such as religious and cultural ones. However, in the context of the Arab world, the use of CALL in language teaching and language acquisition is still minimal. Some examples of these studies were conducted by Almekhlafi (2004), who investigated the influence of interactive multimedia CD-ROM on the performance of sixth grade students with relation to their L2 learning styles. In addition, Oyaid (2009) confirmed that information and communication technologies (ICT) are considered to play a crucial rule in education, especially in the field of language learning and teaching. On the other hand, due to the planning and effort that CALL needs in order to be integrated into the educational systems in Gulf Countries, the attitudinal and cultural adaptions to this type of technology can be a barrier to using CALL in learning and teaching (Al-Kahtani, \& Al-Haider, 2010).

\section{3- Theoretical Framework}

This study examined learners' attitudes towards the use of CALL, which involved using technology to test the implementation of grammatical rules of English as a foreign language in a specific context. Reasoned action theory (RAT), developed by Fishbein $(1963,1967)$, and constructivism were applied as the theoretical framework in order to compare the results of grammar acquisition between the two groups.

Fishbein's RAT is defined as "a cognitive theory that is designed to predict and explain any human behaviour that is under volitional control. It deals with the relationships between beliefs, attitudes, subjective norms, intentions, and behaviour" (Almekhlafi, 2006, p.125). Consequently, this theory was used to examine the learners' attitudes towards language, and generally has been used for this purpose in different educational fields. RAT has been investigated, tested, and validated by many researchers (Almekhlafi, 2006; Eslit, 2017; Nguyen et al., 2018; Zint, 2002). For example, Almekhlafi (2006) used RAT to evaluate the behaviour and achievements of school students towards the use of CALL in learning English in the United Arab Emirates. Also, Zint (2002) used RAT to predict the intention of science teachers to integrate environmental risk education. The term constructivism refers to the concept that learners build knowledge based on constructing upon previous experience. According to Almekhlafi (2006), constructivism is being using in many different educational fields to allow learners to build their own knowledge of subjects. 
For instance, Collins (1991) used technology in the classroom and asserted that technology appeared to be an important tool for constructivists. According to Collins, researchers showed thattechnology-rich classrooms proved to have many significance improvements in the learning outcomes for students. For example, students were able to integrate both verbal and visual thinking skills instead of using only verbal thinking as a result of using technology which helped to construct their knowledge. Also, students can learn different things from different courses, and technology can involve students more in learning.

Moreover, Lebow (1993) pointed out many benefits of the application of constructivism with technology. For example, it promotes self-evaluation for both skills and attitudes towards learning. Also, it supports effective learner engagement in the learning progress. In addition, constructivism provides learners with a learning context that integrates both relatedness and autonomy to that context, as well as presenting the aim of the learning through practising the learning activities. In fact, these benefits of technology come along with the constructive principles. In other words, using CALL could provide significant opportunities for the constructivist approach in relation to the field of language acquisition in particular and education in general. Since constructivism has proven to be an applicable framework for using CALL in education, the current study adopted this approach to analyse the results and compare the groups in order to test the effectiveness of using CALL in grammar learning.

\section{4-Methodology}

This study tested if CALL had an impact on the English grammar acquisition of Saudi university students in their preparation year at Tibah University. The hypothesis of this research was that using extra material on the LMS would improve students' English language competence and assist students in grammar learning. In fact, some research has found that there is no relationship between CALLand the outcomes of English learning skills and a learner's achievement, such as the study conducted by (Barani, 2013) in an Iranian EFL context. On the other hand, some studies asserted that using CALL has facilitated L2 learner's language competence in some skills, such as the study conducted by Rahnavard and Heidar (2016), which indicated that CALL had a positive effect on students' performance in certain English language skills including pronunciation and grammar.

\subsection{Participants}

The sample population in this research consisted of 150 Saudi females, who studyEnglishlanguage as a core module in their preparation year at Taibah University in Saudi Arabia.Each student's first language was Arabic. The students were tested in their English language proficiency usingOxford Online Placement Test and scored at an intermediate level. The participants were placedinto one of two groups: experimental or control. Each group consisted of 75 students. All the participants were relatively homogenous in their level of English, language, cultural background and age. Both the experimental and control group classes were studying English for a total of 14 hours over eight sessions. The sessions occurred four times a week, usually lasting for about one hour and 40 minutes. The experimental group studied English using the LMS and the text material, while the control group studied the same material through the textbook only. The study lasted for exactly one month.Furthermore, the class teacher was assigned to teach both groups during the conductof this study.

\subsection{Materials}

Three different materials were used to test the hypotheses of this study:

A) Oxford Placement Test (OPT): In order to define and validate the English level of the students for forming a homogeneous group.Students were given the OPT, a proficiency test of EnglishLanaguge. In fact, the OPT is formulated to test and measure a student's capability to use a wide range of English language vocabulary and grammatical forms in a variety of contexts. It also tests a learner's proficiency in using these language forms and measures the use of different resources to communicate in English as a L2 in different contexts.

B) Teaching Materials: The primary teaching materials were drawn from texts produced as part of the Oxford University Press Q: Skills for Success (Special Edition, Level 1) course books. Two books (Listening and Speaking 1 and Reading and Writing 1) were used. Eight units from the books were introduced and taught to the students over a period of eight weeks. A special focus was given on teaching grammar skills and grammatical rules related to each unit.

C) Online Materials: The IQ online integrated digital content from the two books (Listening and Speaking 1 and Reading and Writing 1) of the Oxford University Press Q: Skills for Success program was provided to the students. The online materials included the following: activities which consisted of additional practice and support, videos and online tests, progress monitor, email, discussion board, media centre, resources and language practice. Grammar skills were the only intended focus in the use of these materials. 


\subsection{Procedures}

The following procedure was followed in order to meet the purpose of this study.

First, the 220 potential participants took the OPT test; of these, 150 students were chosen for the study due to their similar levels(intermediate) of English language proficiency. They were randomly assigned to two different groups of 75 , one control group and one experimental group.

The study was conducted over a period of eight weeks. There were four classes per week for one hour and forty minutes each session. The syllabus for both groups was the same except that the control group did not receive any online materials (the digital content of the same course book). All online materials for the experimental group were downloaded to the students' own smartphones and laptops with internet access.

All the participants in both the control and experimental groups studied the material from the textbooks during the English classes. During the eight weeks of teaching, 30 grammatical rules, related examples and activities selected from the books were presented to both groups during the classes. The control group did the activities from the textbooks in class (using printed papers only), and the experimental group did the activities and used resources from the online digital context of the book. Both groups were assigned to do activities related to specific grammar points in each unit. After finishing with the treatment of the assigned grammatical rules over eight weeks, all the participants from both groups took the post-test.

\section{4- Results}

The results of the placement test and the post-test served as the statistical basis for comparing the two groups. The t-test comparison of group means of the placement test resulted in $t=-7.41$, The $t$-test analysis showed that students selected to be in the experimental group had similar English language proficiency $(70.60 \pm)$ compared to the students in the

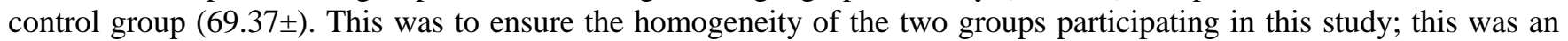
expected result as group membership was randomly assigned, students who are below the average of 70 in the placement test were excluded from the study. However, the results on the post-test showed that the students in the control group and in the experimental group improved their English capability by studying English grammar extensively during the sessions. Nevertheless, the t-test analysis on the post-test results showed that the students in the experimental group improved significantly more when compared to the students in the control group at a significance level of 0.025 .

\section{A-PlacementTest}

H0: $\mu_{\text {control }}=\mu_{\text {experiment }}$

It is hypothesised that the control group is equal to the experimental group on the results of the placement test.

H1: $\mu_{\text {control }} \neq \mu_{\text {experiment }}$

It is hypothesised that the control group is not equal to the experimental group on the results of the placement test. $\alpha=$ 0.025 .

Table 1: Descriptive StatisticsofthePlacement-Test:Control Group/Experimental

\begin{tabular}{|l|l|l|l|l|l|l|l|l|}
\hline & Group & $\mathrm{N}$ & mean & sd & SEM & t & df & p \\
\hline Placement & Control & 75 & 69.37 & 3.598 & 0.608 & 1.032 & 34 & 0.025 \\
\hline & Experimental & 75 & 70.60 & 2.032 & 0.343 & 1.032 & 34 & 0.025 \\
\hline
\end{tabular}

AccordingtoTable1, the means obtained from the placement-test were very close. The experimental grouphadameanof70.60, and the control group had ameanof69.37. Thet-testvalue was $\mathrm{t}=-1.011$, $\mathrm{t}<\mathrm{T}$, weacceptH0. This confirmed thehomogeneityofthegroups; this was expected as the groups were randomly assigned. The studentsof the experimentalgroup onaveragehad the samelanguageproficiency (including grammar capability) comparedtostudentsinthecontrolgroup.

\section{B-Post-Test}

H0: $\mu_{\text {control }}=\mu_{\text {experiment }}$
H1: $\mu_{\text {control }} \neq \mu_{\text {experiment }}$ 
Table 2: Descriptive StatisticsofthePost-Test: Control Group/Experimental

\begin{tabular}{|l|l|l|l|l|l|l|l|l|}
\hline & Group & $\mathrm{N}$ & mean & sd & SEM & t & df & p \\
\hline Posttest & Control & 75 & 80.08 & 3.100 & 0.524 & 2.032 & 34 & 0.025 \\
\hline & Experimental & 75 & 87.77 & 5.579 & 0.943 & & 34 & 0.025 \\
\hline
\end{tabular}

According to Table 2, it can be seen that the experimental group have an average scored of 7.69 that points higher on the grammar post-test than the control group. In other words, the results showed that the experimental group with a mean of 87.77 did better compared to the control group with a mean of 80.08 . The $t$-test value was $t=2.032$ which was significant, so we reject $\mathrm{H} 0$. The students of experimental group on average had significantly better performance on the grammar post-test. It can be concluded that the treatment given to the experimental group had a positive impact on enhancing the students' proficiency on the grammar test, which supported the hypothesis of this study that CALL is an effective language learning tool.

\section{5- Discussion}

The research conducted in this study found that using CALL for extra material to enhance student learning proved to be an effective tool with Saudi learners. The outcome suggests that the approach was in alignment with the precepts of constructivism, which was used as part of the theoretical framework of the present study. Constructivism was implicit in the treatment given to the experimental group. Constructivism asserts that technology in general and CALL in this context might: (a) support self-regulation by promoting skills and attitudes, (b) reinforce the tendency of L2 learners to be engaged in desired learning processes, (c) provide a learning context that promotes autonomy and successful production of the target language. Moreover, the noteworthy difference in results supports the findings of other studies that examined the positive impact of CALL on L2 learning.

CALL has vital potential for not only learning grammar but also for a much wider range English language learning and teaching. CALL could serve many types of learning objectives if used effectively in different contexts, as it can encourage and motivate learners according to their own needs. It also can raise the level of access to information for learning, such as using extra materials as providedin this study to make students more exposed to different grammatical forms that enhance their L2 acquisition. As CALL provides flexibility in learning and language instruction, it better serves the individual's learning differences as well as supporting different cognitive styles and learning strategies. Nevertheless, CALL in this study allowed students to practice more English grammar forms and helped them to control their own learning progress and via the LMS. In fact, as the online materials were very effective and suitable to serve this study's purpose, CALL in general can establish good meaningful and communicative L2 environments. As the LMS had well-designed materials and sufficient exercises on grammar, it indeed offered good practice and a valuable learning environment, which was reflected in the results of the experimental group. The significant improved performance of students in this study, which was clear in the post-test, revealed the effectiveness of CALL when utilized to meet this study goals which helped learners with better language acquisition in general and grammar in particular.

\section{Conclusion}

The purpose of this study was to investigate the impact of CALL on the acquisition of grammar by Saudi learners in their preparatory year. The results showed that there was a significant difference in students' language competence in grammar between learners who used CALL to practice with the extra materials and the learners who used the textbooks only in learning grammar. The research results were in alignment with the outcomes of previous studies, such as Alresheed et al. (2015), Barani (2012), Eslit (2017), Hashmi (2016), Hedayati et al. (2018), Pirasteh (2014), and Rahnavard and Heidar (2016). Moreover, the results indicated that more practice of different language forms as supplementary material increases a learner's performance in different L2 skills. Thus, to increase L2 learners use of CALL, learners should be guided and trained on using CALL more effectively and continuously. In fact, the use of CALL should be supported in all sectors of educational institutions in order to enhance learners' experiences and increase their seconed/forignlanguage competence. In addition, learners who use CALL should be aware of the positive impact that CALL has on improving their language proficiency and maintaining their language competence.

However, the current study has several limitations. First, the number of participants was small, which may influence the validity of the findings of this study. Therefore, research with a larger number of students would be more powerful in terms of the statistical tests. Also, the participants in this study were adult university learners. Thus, more studies could be conducted to find out the impact of CALL on learning L2 grammar among younger learners, as age is considered to be a vital factor in foreign/second language acquisition. 


\section{References}

Abraham, R. (1985). Field independence-dependence and the teaching of grammar. TESOL Quarterly, 19, 689-702.

Al Abdel Halim, A. (2009). Designing a computer-assisted language learning program (CALL) and measuring its effect on Jordanian secondary school students' reading comprehension in English (Unpublished doctoral dissertation). Yarmouk University, Irbid, Jordan.

Al-Kahtani, S. \& Al-Haider, S. (2010). Factors affecting the use of CALL by EFL female faculty members in Saudi higher education: Current status. JALT Call Journal, 6(3), 153-170.

Almekhlafi, A. G. (2004). The effect of interactive multimedia on learning English as a second language. Proceedings of the Fifth Annual UAE University Research Conference (Vol. 2).245-267 Al-Ain University, United Arab Emirates.

Almekhlafi, A. G. (2006). The effect of computer assisted language learning (CALL) on United Arab Emirates English as a foreign language (EFL) school students' achievement and attitude. Journal of Interactive Learning Research,17(2),121-142.

Al-Qomoul, M. (2005). The effect of using an instructional software program of English language functions on the basic stage students' achievements (Unpublished doctoral dissertation). Amman Arab University for Graduate Studies, Amman, Jordan

Alresheed, S., Leask, M., \&Raiker, A. (2015). Integrating computer-assisted language learning in Saudi schools: A change model. TOJET: The Turkish Online Journal of Educational Technology, 14(4), 69-77.

Alshumaim, Y., \& Alhassan, R. (2010). Current availability and use of ICT among secondary EFL teachers in Saudi Arabia: Possibilities and reality. In Z. Abas, I. Jung, \& J. Luca (Eds.), Proceedings of Global Learn Asia Pacific 2010--Global Conference on Learning and Technology (pp. 523-532). Penang, Malaysia: Association for the Advancement of Computing in Education (AACE).

Alsouki, S. (2001). The effect of using computers in the teaching of L2 composition on the writing performance of tenth grade students in Amman private schools(Unpublished master's thesis). University of Jordan, Amman, Jordan.

Barani, G. (2012). The impact of computer assisted language learning (CALL) on vocabulary achievement of Iranian university students EFL learners, International Journal of Basic Sciences \& Applied Research,2(5), 531-537.

Bataineh, R., \& Bani Hani, N. (2011). The effect of a CALL program on Jordanian sixth-grade students' achievement. Teaching English with Technology, 11(3), 3-24.

Beatty, K. (2003).Teaching and researching computer assisted language learning. New York, NY: Longman.

Blake, R. (2000). Computer-mediated communication: A window on L2 Spanish interlanguage. Language Learning \& Technology,4(1), 120-136.

Chapelle, C. A. (2001). Computer applications in second language acquisition. New York, NY: Cambridge.

Chapelle,C. A.(2008).Technology and second language acquisition.Annual Review of Applied Linguistics,27(3),98114.

Crossman, D. M. (1997). The evolution of the world wide web as an emerging technology tool. In B.H. Kahn, (Ed.),Web-based instruction (pp.19-25). NJ, Englewood Cliffs: Educational Technology Publications.

Doughty, C. (1991). Second language instruction does make a difference: Evidence from an empirical study of SL relativization. Studies in Second Language Acquisition, 13, 431-469.

Eslit, E. (2017).Computer assisted language teaching: Learning without dust (Unpublished master's thesis). St. Michael's College, Iligan City, Philippines.

Fishbein, M. (1963). An investigation of the relationships between beliefs about an object and the attitude toward that object. Human Relations, 16, 233-240.

Fishbein, M. (1967). Attitude and the prediction of behavior. In M. Fishbein (Ed.), Readings in attitude theory and measurement (pp. 477-492). New York, NY: John Wiley \& Sons.

Hashmi, N. (2016). Computer-assisted language learning (CALL) in the EFL classroom and its impact on effective teaching-learning process in Saudi Arabia. International Journal of Applied Linguistics \& English Literature,5(2) 202-206.

Hedayati, M., \& Reynolds, B., \&Bown, A. (2018). The impact of computer-assisted language learning training on teachers' practices. Journal of Language Teaching and Research, 9(6), 1127-1137.

Hulstijn, J. H. (2000). The use of computer technology in experimental studies of some techniques and some ongoing studies. Language Learning \& Technology, 3(2), 32-43.

Lebow, D. (1993). Constructivist values for instructional systems design: Five principles toward a new mindset. Educational Technology, Research, and Development, 41(3), 4-16.

Levy, M. (1997). CALL: Context and conceptualization. Oxford, UK: Oxford University Press.

Levy, M., \&Stockwell, G. (2007). CALL Dimensions. Mahwah, NJ: Erlbaum. 
Marty, F. (1981). Reflections on the use of computers in second language acquisitionSystem, 9(2), 85-98.

Nagata, N. (1993). Intelligent computer feedback for second language instruction. The Modern Language Journal, 77(3), 330-339.

Nguyen, Q. A., Hens, L., MacAlister, C., Johnson, L., Lebel, B., Tan, S. B., Nguyen, H. M. and Lebel, L., (2018). Theory of reasoned action as a framework for communicating climate risk: A case study of schoolchildren in the Mekong Delta in Vietnam. Sustainability, 10(6), 1-14.

Oyaid, A. A. (2009). Education policy in Saudi Arabia and its relation to secondary school teachers' ICT use, perceptions, and views of the future of ICT in education (Unpublished doctoral dissertation). University of Exeter, Exeter, UK.

Pirasteh, P. (2014). The effectiveness of computer-assisted language learning (CALL) on learning grammar by Iranian EFL learners. Procedia - Social and Behavioral Sciences, 98, 1422-1427.

Pusack, J. P., \& Otto, S. K. (1990). Priority instruction: Applying instructional technologies. Foreign Language Annals, 23(5), 409-417.

Rahnavard, F., \&MashhadiHeidar, D. (2016). The impact of computer-assisted language learning (CALL)/ web-based instruction on improving learners' pronunciation ability. IJREE, 2(1), 49-57.

Saeidi, M., \& Yusef, M. (2012). The effect of computer-assisted language learning on reading comprehension in an Iranian EFL context. In L. Bradley \& S. Thouësny (Eds.), EUROCALL Conference 22-25 August 2012, Proceedings (pp. 259- 263). Gothenburg, Sweden: Research-publishing.net.

Sanz, C., \& Morgan-Short, K. (2004). Positive evidence versus explicit rule presentation and explicit negative feedback: A computer assisted study. Language Learning, 54(1), 35-78.

Skehan, P. (1998). A cognitive approach to language learning. Oxford, UK: Oxford University Press.

Smith, B. (2004). Computer-mediated negotiated interaction and lexical acquisition. Studies in Second Language Acquisition, 26, 365-398.

Warschauer, M. (1996). Computer-assisted language learning: An introduction. In S. Fotos (Ed.), Multimedia Language Teaching (pp. 3-20). Tokyo, Japan: Logos International.

Yoshii, M., \&Flaitz, J. (2002). Second language incidental vocabulary retention: The effect of text and picture annotation types. CALICO Journal, 20(1), 33-58.

Zint, M. (2002). Comparing three attitude-behavior theories for predicting science teachers' intentions. Journal of Research in Science Teaching, 39(9), 819-844. 